\title{
Health-related quality of life in Slovenian patients with colorectal cancer: a single tertiary care center study
}

\author{
Jan Grosek ${ }^{1}$ Jerica Novak², Katja Kitek², Alta Bajric ${ }^{3}$, Ana Majdic ${ }^{3}$, Jurij Ales Kosir ${ }^{1}$,
} Ales Tomazic ${ }^{1}$

\author{
${ }^{1}$ Department of Abdominal Surgery, Ljubljana University Medical Center, Ljubljana, Slovenia \\ ${ }^{2}$ Department of Surgical Oncology, Ljubljana Institute of Oncology, Ljubljana, Slovenia. \\ ${ }^{3}$ Medical Faculty, University of Ljubljana, Ljubljana
}

Radiol Oncol 2019; 53(2): 231-237.

Received 12 December 2018

Accepted 02 February 2019

Correspondence to: Jan Grosek, M.D., Ph.D., Department of Abdominal Surgery, Ljubljana University Medical Center, Zaloška cesta 7, SI-1000 Ljubljana, Slovenia. Phone: +386 1522 4788; Fax: +386 1522 2209; E-mail: jan.grosek@kclj.si

Disclosure: No potential conflicts of interest were disclosed.

Background. The aim of this study was to evaluate the influence of the surgical treatment on Slovenian colorectal cancer patients' health-related quality of life and to compare the results to the health-related quality of life of the general Slovenian population.

Patients and methods. A total of 413 patients with colorectal cancer operated on at the Abdominal Surgery Department at the Ljubljana University Medical Center between January 1st, 2016 and December 31st, 2017 were sent two standardized and validated questionnaires: the EORTC QLQ-C30 version 3 and EORTC QLQ-CR29. The questionnaires were returned by 197 patients.

Results. Compared to the general population, poorer physical $(p<0.001)$, role $(p=0.002)$, cognitive $(p=0.021)$, and social functioning $(p<0.001)$ with higher frequency of constipation $(p<0.001)$, diarrhea $(p<0.001)$, and financial difficulties $(p<0.001$ ) were reported by the colorectal patients. Female patients reported lower cognitive $(p=0.034)$ and emotional $(p=0.008)$ functioning, as well as higher frequency of bloating $(p=0.049)$ and hair loss $(p=0.01)$. Compared to the younger group of patients, lower physical functioning $(p<0.001)$ and higher urinary frequency $(p=0.007)$, urinary incontinence $(p=0.007)$, buttock pain $(p=0.007)$, and anxiety regarding body weight $(p=0.031)$ were detected among the older group of colorectal patients.

Conclusions. The global health status of colorectal patients in Slovenia is comparable to that of the general Slovenian population, but there is a significantly lower level in some of the quality-of-life scales.

Key words: health-related quality of life; colorectal cancer; colorectal surgery; Slovenia

\section{Introduction}

Colorectal cancer (CRC) is an important cause of death as well as decreased quality of life. Worldwide, CRC is the third most commonly diagnosed malignancy and the fourth most common cause of death. ${ }^{1}$ The incidence of CRC is higher in the developed countries. ${ }^{2}$ The 5-year and 10-year survival rates of operable and localized colorectal cancer are $60 \%$ and $50 \%$, respectively. ${ }^{3}$

In Slovenia, 11,269 patients $(56 \%$ men, $44 \%$ women) with CRC were still alive at the end of 2015. CRC is the fourth most commonly diagnosed malignancy among Slovenian cancer patients. ${ }^{4}$ In 2015, 1,356 patients were diagnosed with CRC ( $58 \%$ men, $42 \%$ women). Colon cancer was found 
most frequently $(63 \%)$, followed by cancer of the rectum and rectosigmoid junction. (37\%). ${ }^{4}$

Impaired health-related quality of life (QoL) in CRC patients may result from the disease itself and/or treatment. ${ }^{5}$ It can be described as psychophysical, functional, and emotional disruption or social impairment. ${ }^{6,7}$ Standardized questionnaires are used to evaluate QoL in cancer patients. ${ }^{8}$ The most commonly used questionnaire for evaluating QoL in oncology is the EORTC QLQ-C30 questionnaire, launched by the European Organisation for Research and Treatment of Cancer (EORTC). ${ }^{9}$ It has been translated into many languages, including Slovenian..$^{10}$ The reference values of the EORTC QLQ-C30 questionnaire for the general Slovenian population have already been obtained and published. ${ }^{11}$ Moreover, the EORTC developed the colorectal QoL module EORTC QLQ-CR29, which has been used as an addition to the EORTC QLQ-C30 to evaluate QoL in CRC patients. ${ }^{12}$

The aim of this study was to evaluate QoL in CRC patients after colorectal surgery and to compare the results with the reference data from the general Slovenian population.

\section{Patients and methods}

\section{Patients}

QoL was evaluated for patients with CRC, stages I$\mathrm{IV}$, with and without metastatic disease, operated on at the Abdominal Surgery Department of the Ljubljana University Medical Center from January $1^{\text {st }}, 2016$ to January $31^{\text {st }}, 2017$. Patients still alive on January $1^{\text {st }}, 2018$ were included. A patient chart review was performed. A total of 413 patients met the inclusion criteria and were sent the questionnaire; of these, 197 patients (116 male, 81 female) returned the questionnaire. Patients at least one year and no more than two years from the initial operation were included in the study.

\section{Questionnaires}

For the purpose of this study, the standardized questionnaires EORTC QLQ-C30 and QLQ-CR29 were utilized. The questionnaires were translated into Slovenian.

The EORTC QLQ-C30 questionnaire consists of three scoring scales that grade function, symptoms, and global health. The scales include one or more questions. Each question has four response options from $1=$ not at all to $4=$ very much. A higher score corresponds to a poorer result and more symptoms present. On the other hand, global health status is categorized with seven-point scoring scale on which a higher score corresponds to greater wellbeing and higher quality of life.

The EORTC QLQ-CR29 questionnaire consists of two scoring scales that grade function and symptoms, and it has specifically been used to assess QoL in CRC patients. As for the EORTC QLQ-C30, the responses range from 1 to 4 and a higher score defines a poorer outcome, with exception of the response for sexual interest, for which a higher score correlates with a better result.

\section{Statistical analysis}

Because the scoring scales consist of one or more questions (anxiety on the EORTC QLQ-CR29 and cognitive functions on the EORTC-CR29), a raw score (RS) was calculated for each scoring scale. Linear transformation was used to standardize the RS and the transformed recorded answers into dimensions ranging from 0 to 100 . Higher scores on functional scoring scales correlated with better functions in patients and, on the other hand, higher scores on symptom scoring scales correlated with poorer outcomes. For the linear transformation, the following formulas were applied:

- For functional scoring scales: $\mathrm{S}=$;

- For symptom scoring scales: $\mathrm{S}=$;

- For global health-status: S.

The numerical variables were represented by means and standard deviations. The differences between numerical variables were tested using Student's $t$-test. For the purpose of the statistical analysis, patients were divided into two age groups according to the reported median age of 73 years. First group included patients from 39 to 73 years and the second group patients from 74 to 92 years. The association between age groups and sexes was tested using the Mann-Whitney test. A pvalue $<0.05$ was considered statistically significant. Statistical analyses were performed using SPSS software (IBM Corp., version 24.0 Armonk, NY).

Approval for the study was obtained from the Medical Ethics Committee of the Republic of Slovenia, the Protocol Review Board (MZ 012048/2018-6). Written consent from all patients included was provided prior to study enrollment.

\section{Results}

A total of 413 patients received the questionnaire, and the response rate was $47.7 \%$ (197 patients). 
Characteristics of the study population are shown in Table 1.

\section{EORTC QLQ-C3 Scoring scale}

When the average scores of the EORTC QLQ-C30 in the general Slovenian population and in patients with CRC were compared, statistically significant differences in QoL were detected. Physical, role, cognitive, and social functioning scores were significantly lower in patients with CRC compared to the general population. Compared to the general population, CRC patients more often experienced symptoms as constipation and diarrhea. Moreover, compared to general population, financial difficulties were also more often reported by the CRC patients. No other statistically significant differences were detected between CRC patients and the general population (Table 2). ${ }^{11}$

When comparing QoL among CRC patients, statistically significant lower scores for cognitive and emotional functioning were detected in females. No other statistically significant differences between the sexes were detected (Table 3).

When comparing the different age groups of the CRC patients (younger group 39-73 years, older group 74-92 years), statistically significant lower physical functioning scores were reported among the older patients. In addition, insomnia and dyspnea were more often reported among the older patients compared to the younger ones (Table 4).

\section{EORTC QLQ-CR29 Scoring scale}

Females more often reported bloating and hair loss. No other statistically significant differences in the rate of reporting other symptoms and in the scoring for mental health were found between the sexes (Table 5).

Compared to younger patients, older patients more often reported symptoms such as urinary frequency, urinary incontinence, and buttock pain. Older patients were also more concerned regarding their weight (Table 6).

\section{Discussion}

QoL is a substantial factor when outcomes and effects of the disease on CRC patients after multimodal treatment are evaluated. ${ }^{13}$ In Slovenia, the evaluation of QoL in CRC patients is not yet systematically used. To the best of our knowledge, this is the first study evaluating QoL in CRC pa-
TABLE 1. Characteristics of the study population

\begin{tabular}{lccc}
\hline & $\begin{array}{c}\text { Responders } \\
\mathbf{n} 197\end{array}$ & $\begin{array}{c}\text { Non- } \\
\text { responders } \\
\mathbf{n} 216\end{array}$ & p-value \\
\hline Median age (IQR) & $72(62-79)$ & $74(65-81)$ & 0.016 \\
Sex & $116(58.9)$ & $133(61.5)$ & 0.603 \\
Male (\%) & $81(41.1)$ & $83(38.5)$ & \\
Female (\%) & & & \\
& & & \\
Complications & $175(88.8)$ & $150(69.4)$ & $<0.001$ \\
Not reported & $15(7.6)$ & $32(14.8)$ & \\
Severe* (\%) & & & 0.208 \\
& $80(40.6)$ & $101(46.8)$ & 0.033 \\
Operation & $8(4.1)$ & $17(7.9)$ & 0.152 \\
Right hemicolectomy & $26(13.2)$ & $19(8.8)$ & 0.542 \\
Extended right hemicolectomy & $10(5.1)$ & $14(6.5)$ & 0.312 \\
Left hemicolectomy & $4(2)$ & $8(3.7)$ & 0.181 \\
Hartmann's procedure & $13(6.6)$ & $8(3.7)$ & 0.147 \\
Rectosigmoid resection & $46(23.4)$ & $38(17.6)$ & 0.298 \\
Low anterior resection & $2(1)$ & $5(2.3)$ & 0.396 \\
Sigmoid resection & $5(2.5)$ & $3(1.4)$ & $2(0.9)$ \\
Subtotal colectomy & $4(2)$ & $2(0.9)$ & 0.613 \\
Total colectomy & $1(0.5)$ & & \\
Segmental resections of the colon & & & \\
Other procedures & & & \\
\hline
\end{tabular}

Clavien-Dindo classification 3 to $5 ; \mathrm{IQR}=$ interquartile range; $\mathrm{n}=$ number of patients

tients after surgery and comparing it with QoL for the general Slovenian population.

This study found no statistical differences in the reported global health score between CRC patients and the general Slovenian population. The results are comparable to other similar studies. ${ }^{6,14-17}$ On the other hand, compared to the general Slovenian population, our CRC patients reported poorer physical, cognitive, and social functioning. Moreover, they also more frequently reported symptoms such as constipation, diarrhea, and financial difficulties compared to the general Slovenian population. Similar results have been observed in other published studies. ${ }^{15,17}$ A comparable discovery was made by Rauch et al., in which patients more frequently reported lower physical functioning but also had greater levels of pain than the general population. ${ }^{14}$

When comparing the responding and non-responding group of CRC patients, a higher rate of major postoperative complications was observed in the non-responding group. Postoperative complications that lead to reoperation, longer hospitalization, or stoma formation can greatly alter QoL in CRC patients. In our study, the reported satisfaction with QoL in the responding group may therefore be due to the lower rates of major postoperative complications. Nevertheless, patients in 
TABLE 2. Comparison of the scores for all scales of the EORTC QLQ-C30 between CRC patients and the general Slovenian population

\begin{tabular}{|c|c|c|c|c|c|c|c|}
\hline & \multicolumn{5}{|c|}{ Colorectal patients } & \multirow{2}{*}{$\begin{array}{c}\text { General Slovenian } \\
\text { population } \\
\text { M (SD) }\end{array}$} & \multirow{2}{*}{$p$-value } \\
\hline & Min & Max & $M(S D)$ & Me (IQR) & n & & \\
\hline \multicolumn{8}{|l|}{ Functional scoring scale } \\
\hline Role functions & 0 & 100 & $82.7(26.8)$ & $100(67-100)$ & 196 & $88.7(20.1)$ & 0.002 \\
\hline Cognitive functions & 0 & 100 & $87.2(18.1)$ & $100(83-100)$ & 197 & $90.2(16)$ & 0.021 \\
\hline Social functions & 0 & 100 & $82.1(24)$ & $100(67-100)$ & 197 & $90.9(17.3)$ & $<0.001$ \\
\hline \multicolumn{8}{|l|}{ Symptom scoring scale } \\
\hline Dyspnea & 0 & 100 & $6.2(16.1)$ & $0(0-0)$ & 197 & $5.3(15.3)$ & 0.928 \\
\hline Insomnia & 0 & 100 & $22.4(27.5)$ & $0(0-33)$ & 197 & $19.8(25.1)$ & 0.182 \\
\hline Loss of appetite & 0 & 100 & $5.6(17.2)$ & $0(0-0)$ & 195 & $5.3(15.5)$ & 0.791 \\
\hline Fatigue & 0 & 100 & $22.2(22.2)$ & $22(0-33)$ & 197 & $19.8(19.8)$ & 0.126 \\
\hline Pain & 0 & 100 & $13.8(21.8)$ & $0(0-17)$ & 195 & $14.5(20.2)$ & 0.633 \\
\hline Financial impact of disease & 0 & 100 & $14.2(26.6)$ & $0(0-33)$ & 196 & $6.6(17.5)$ & $<0.001$ \\
\hline \multicolumn{8}{|l|}{ Global health status } \\
\hline Global health status & 17 & 100 & $68.3(20.5)$ & $67(50-83)$ & 197 & $71.1(21.4)$ & 0.058 \\
\hline
\end{tabular}

$I Q R=$ interquartile range; $M a x=$ maximum value; $M e=$ median; $M i n=$ minimal value; $S D=$ standard deviation; $n=$ number of patients

TABLE 3. Comparison of the scores for all the scales of the EORTC QLQ-C30 by sex.

\begin{tabular}{|c|c|c|c|c|c|c|c|}
\hline & \multicolumn{3}{|c|}{ Male } & \multicolumn{3}{|c|}{ Female } & \multirow{2}{*}{$p$-value } \\
\hline & $M(S D)$ & Me (IQR) & $n$ & $M(S D)$ & Me (IQR) & $n$ & \\
\hline \multicolumn{8}{|l|}{ Functional scoring scale } \\
\hline Physical functions & $82.9(19.1)$ & $87(80-100)$ & 116 & $83.1(21.8)$ & $93(80-100)$ & 81 & 0.584 \\
\hline Role functions & $84.1(23.2)$ & $100(67-100)$ & 115 & $80.7(31.2)$ & $100(67-100)$ & 81 & 0.982 \\
\hline Cognitive functions & $89.8(15.2)$ & $100(83-100)$ & 116 & $83.5(21)$ & $83(67-100)$ & 81 & 0.034 \\
\hline Emotional functions & $85.7(14.9)$ & $92(75-100)$ & 116 & $80(17.5)$ & $83(75-92)$ & 81 & 0.008 \\
\hline Social functions & $81.5(22.7)$ & $83(67-100)$ & 116 & $82.9(25.8)$ & $100(67-100)$ & 81 & 0.329 \\
\hline \multicolumn{8}{|l|}{ Symptom scoring scale } \\
\hline Dyspnea & $6(16.2)$ & $0(0-0)$ & 116 & $6.5(16.1)$ & $0(0-0)$ & 81 & 0.570 \\
\hline Insomnia & $21.2(26.9)$ & $0(0-33)$ & 116 & $24.2(28.4)$ & $33(0-33)$ & 81 & 0.450 \\
\hline Loss of appetite & $4.3(15.6)$ & $0(0-0)$ & 115 & $7.5(19.1)$ & $0(0-0)$ & 80 & 0.115 \\
\hline Nausea and vomiting & $3.1(8.7)$ & $0(0-0)$ & 115 & $2.7(7.3)$ & $0(0-0)$ & 80 & 0.934 \\
\hline Constipation & $13.6(22.9)$ & $0(0-33)$ & 115 & $12.7(22)$ & $0(0-33)$ & 81 & 0.903 \\
\hline Diarrhea & $12.8(22)$ & $0(0-33)$ & 115 & $12.3(23.8)$ & $0(0-33)$ & 81 & 0.641 \\
\hline Fatigue & $19.9(21)$ & $11(0-33)$ & 116 & $25.5(23.5)$ & $22(0-33)$ & 81 & 0.110 \\
\hline Pain & $12.3(19.8)$ & $0(0-17)$ & 114 & $15.8(24.4)$ & $0(0-22)$ & 81 & 0.338 \\
\hline Financial impact of disease & $13.5(26.7)$ & $0(0-33)$ & 116 & $15.4(26.5)$ & $0(0-33)$ & 80 & 0.441 \\
\hline \multicolumn{8}{|l|}{ Global health status } \\
\hline Global health status & $68.1(21.4)$ & $67(50-83)$ & 116 & $68.6(19.3)$ & $67(50-83)$ & 81 & 0.903 \\
\hline
\end{tabular}

$I Q R=$ interquartile range; $M=$ mean; $M e=$ median; $n=$ number of patients $S D=$ standard deviation 
TABLE 4. Comparison of the scores for all the scales of the EORTC QLQ-C30 by age groups

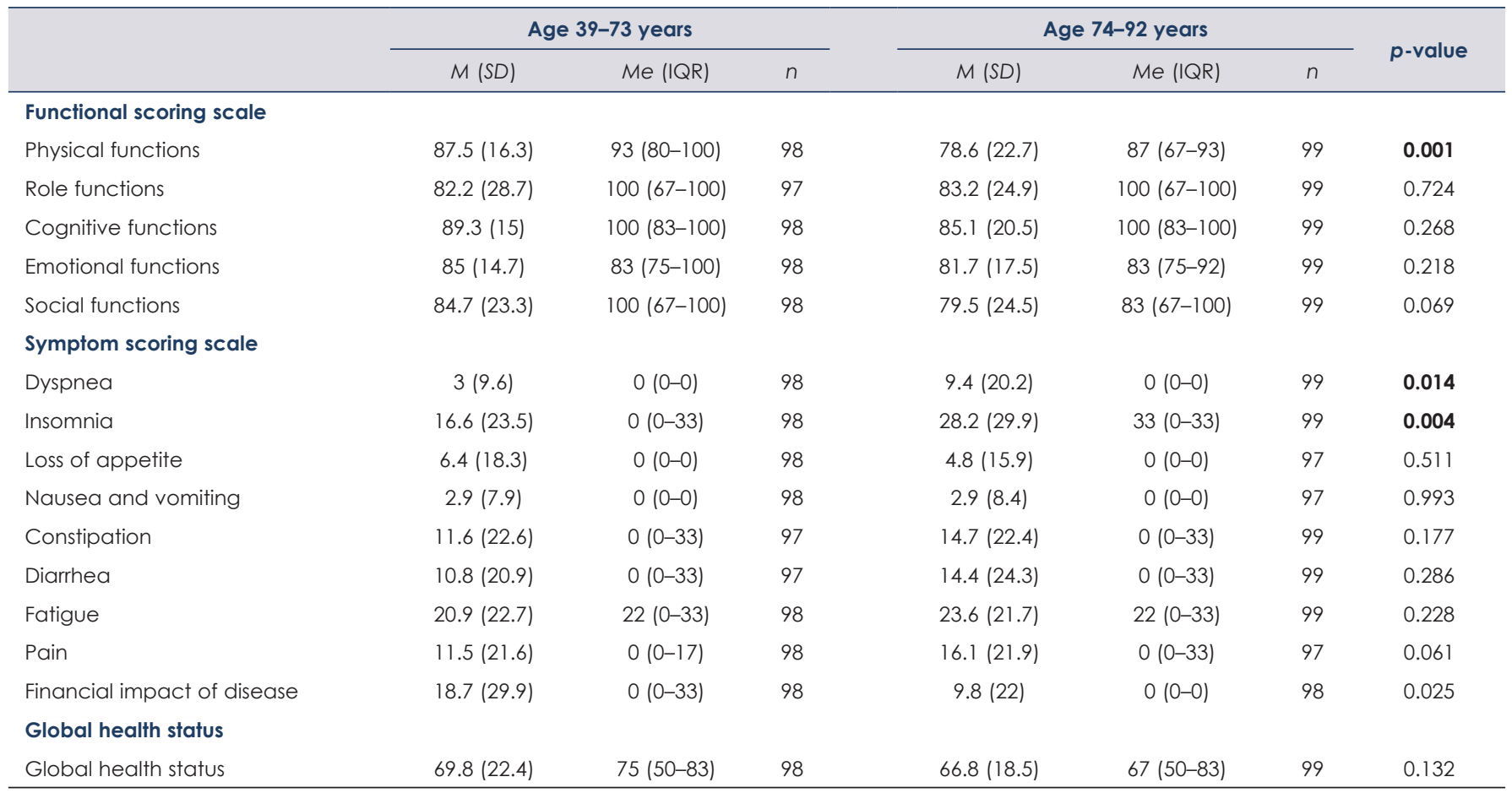

$I Q R=$ interquartile range; $M=$ mean; $M e=$ median; $S D=$ standard deviation; $n=$ number of patients

TABLE 5. Comparison of the scores for all the scales of the EORTC QLQ-CR29 by sex

\begin{tabular}{|c|c|c|c|c|c|c|c|}
\hline & \multicolumn{3}{|c|}{ Male } & \multicolumn{3}{|c|}{ Female } & \multirow{2}{*}{$p$-value } \\
\hline & $M(S D)$ & Me (IQR) & $\mathrm{n}$ & $M(S D)$ & Me (IQR) & $\mathrm{n}$ & \\
\hline \multicolumn{8}{|l|}{ Symptom scoring scale } \\
\hline Urinary incontinence & $9.1(18.3)$ & $0(0-0)$ & 116 & $9.1(17.5)$ & $0(0-0)$ & 80 & 0.941 \\
\hline Dysuria & $4.6(13.1)$ & $0(0-0)$ & 115 & $2.4(8.7)$ & $0(0-0)$ & 81 & 0.266 \\
\hline Bloating & $18.9(24.5)$ & $0(0-33)$ & 116 & $25.4(26)$ & $33(0-33)$ & 81 & 0.049 \\
\hline Blood \& mucus in stool & $3.4(11.7)$ & $0(0-0)$ & 116 & $3.5(11.1)$ & $0(0-0)$ & 81 & 0.939 \\
\hline Dry mouth & $21(25.2)$ & $16.5(0-33)$ & 116 & $24.7(28.8)$ & $0(0-33)$ & 81 & 0.503 \\
\hline Hair loss & $1.4(6.7)$ & $0(0-0)$ & 116 & 5.7 (15.5) & $0(0-0)$ & 81 & 0.010 \\
\hline Sore skin & $14(22.4)$ & $0(0-33)$ & 88 & $18.5(25.1)$ & $0(0-33)$ & 70 & 0.212 \\
\hline Stool frequency & $11.8(18.3)$ & $0(0-17)$ & 89 & $11.6(16.4)$ & $0(0-17)$ & 71 & 0.772 \\
\hline Embarrassment & $8.3(18.3)$ & $0(0-0)$ & 88 & $9.3(20.6)$ & $0(0-0)$ & 68 & 0.925 \\
\hline \multicolumn{8}{|l|}{ Mental health } \\
\hline Anxiety & $57.1(29.1)$ & $67(33-67)$ & 114 & $49.8(26.6)$ & $67(33-67)$ & 81 & 0.069 \\
\hline Weight & $78.7(28.1)$ & $100(67-100)$ & 115 & $79.9(29.2)$ & $100(67-100)$ & 81 & 0.563 \\
\hline Body image & $86.5(20.2)$ & $100(78-100)$ & 115 & $87.3(21)$ & $100(78-100)$ & 81 & 0.708 \\
\hline
\end{tabular}


TABLE 6. Comparison of the scores for all the scales of the EORTC QLQ-CR29 by age groups

\begin{tabular}{|c|c|c|c|c|c|c|c|}
\hline & \multicolumn{3}{|c|}{ Age $39-73$ years } & \multicolumn{3}{|c|}{ Age $74-92$ years } & \multirow{2}{*}{$p$-value } \\
\hline & $M(S D)$ & $M e(I Q R)$ & $n$ & $M(S D)$ & $M e(I Q R)$ & $n$ & \\
\hline \multicolumn{8}{|l|}{ Symptom scoring scale } \\
\hline Urinary incontinence & $5.9(15.1)$ & $0(0-0)$ & 98 & $12.4(19.9)$ & $0(0-33)$ & 98 & 0.007 \\
\hline Dysuria & $3(9.6)$ & $0(0-0)$ & 98 & $4.4(13.2)$ & $0(0-0)$ & 98 & 0.607 \\
\hline Abdominal pain & $8.8(14.6)$ & $0(0-33)$ & 98 & $14.1(20.2)$ & $0(0-33)$ & 99 & 0.087 \\
\hline Blood \& mucus in stool & $4.1(14)$ & $0(0-0)$ & 98 & $2.8(8.2)$ & $0(0-0)$ & 99 & 0.938 \\
\hline Dry mouth & $18.7(24.2)$ & $0(0-33)$ & 98 & $26.2(28.7)$ & $33(0-33)$ & 99 & 0.069 \\
\hline Hair loss & $4.4(14)$ & $0(0-0)$ & 98 & $2(7.9)$ & $0(0-0)$ & 99 & 0.193 \\
\hline Taste & $7.1(17.4)$ & $0(0-0)$ & 98 & $9.5(22.4)$ & $0(0-0)$ & 98 & 0.648 \\
\hline \multicolumn{8}{|l|}{ No stoma } \\
\hline Embarrassment & $7.8(17.7)$ & $0(0-0)$ & 81 & $9.7(21)$ & $0(0-0)$ & 75 & 0.550 \\
\hline \multicolumn{8}{|l|}{ Mental health } \\
\hline Anxiety & $51.4(30.1)$ & $67(33-67)$ & 98 & $56.8(26.1)$ & $67(33-67)$ & 97 & 0.227 \\
\hline Weight & $74.6(30.8)$ & $100(67-100)$ & 98 & $83.7(25.4)$ & $100(67-100)$ & 98 & 0.031 \\
\hline Body image & $84.9(22.8)$ & $100(78-100)$ & 98 & $88.8(17.7)$ & $100(78-100)$ & 98 & 0.156 \\
\hline
\end{tabular}

$I Q R=$ interquartile range; $M=$ mean; $M e=$ median; $S D=$ standard deviation; $n=$ number of patients

the responding group were also younger (median age 73 years, compared to 75.5 years in the nonresponding group, respectively; $p=0.016$ ), which can also be an important factor contributing to reported better QoL in this group of patients. As determined in a study by Velenik et al., reported QoL in the general Slovenian population decreases with age. ${ }^{11}$

In the general Slovenian population, a comparison of QoL between the sexes showed a statistically significant difference in reported physical functioning, which was poorer among females $(p<$ 0.000 ). No other statistically significant differences in functioning were reported. ${ }^{11}$ On the other hand, when comparing CRC patients by sex, female CRC patients more frequently reported lower cognitive and emotional functioning compared to males ( $p=$ 0.034 and 0.008 , respectively). Females also more frequently reported bloating and hair loss, and the difference was statistically significant $(p=0.049$ and 0.01 , respectively). No other statistically significant differences were observed between the sexes. Similar to our study, Adams et al. discovered that female CRC patients, compared to males, more often reported lower cognitive and emotional functioning, and also lower physical and social functioning. ${ }^{18}$ As the results show, female patients may need more emotional support following treatment. Therefore open discussion of the symptoms and suitable referrals for additional support or mental health treatments should be made during followups. $^{19}$

Reported QoL in the general Slovenian population is lower among the elderly. ${ }^{11}$ This phenomenon has also been reported by other European researchers. ${ }^{20-22}$ Comparing QoL of different age groups shows lower physical functioning of older patients. $(p=0.001)$. Our results correlate with similar reports in the literature. ${ }^{23-25}$ Statistically significant differences between age groups were discovered when reporting the frequency of symptoms of urinary frequency, urinary incontinence, and buttock pain. On the other hand, Japanese and American studies discovered better QoL in elderly patients. ${ }^{26,27}$ One can conclude that society and environment significantly influence individual evaluations of QoL.

Our study has limitations. First of all, the response rate was low (47.7\%). For optimal results, the respond rate should be above $85 \%$. This could be achieved by systematically distributing the questionnaire to CRC patients at follow-ups. Therefore, not only the feedback but also immediately addressing patients' key issues with possible 
additional referrals could be achieved. Another limitation is that the study was performed at a single tertiary center in Slovenia. For better results and optimal insight into QoL in CRC patients, a systematic multicenter study including all tertiary and regional centers in Slovenia should be carried out. The questionnaires should be given to CRC patients prior to surgery or neoadjuvant treatment, 1 month after surgery, and 1 and 5 years after treatment. In this way, comprehensive insight into QoL in CRC patients could be obtained, evaluating not only the influence of surgery but also the influence of neoadjuvant treatment on QoL in these patients.

\section{Conclusions}

This is the first Slovenian study comparing QoL in CRC patients with the general Slovenian population. The global health status of CRC patients in Slovenia is comparable to that of the general Slovenian population, but there is a significantly lower score on some of the QoL scales. For further research, a systematic multicenter study, including CRC patients from all Slovenian tertiary centers, should be performed with the aim of improving QoL for these patients with multidisciplinary follow-up treatment.

\section{Acknowledgements}

We wish to thank Ms. Vanja Erčulj, statistician who performed all necessary statistical calculations.

\section{References}

1. Ferlay J, Soerjomataram I, Ervik M, Dikshit R, Eser S, Mathers C, et al. Cancer incidence and mortality worldwide: sources, methods and major patterns in GLOBOCAN 2012. Int J Cancer 2015; 136: E359-86. doi: 10.1002/ijc.29210

2. Arnold M, Sierra MS, Laversanne M, Soerjomataram I, Jemal A, Bray F. Global patterns and trends in colorectal cancer incidence and mortality. Gut 2017; 66: 683-91. doi: 10.1136/gutjnl-2015-310912

3. van Gijn W, Marinjen CA, Nagtegaal ID, Kranenbarg EM, Putter H, Wiggers T, et al. Dutch Colorectal Cancer Group. Preoperative radiotherapy combined with total mesorectal excision for resectable rectal cancer: 12-year followup of the multicenter, randomized controlled TME trial. Lancet Oncol 2011; 12: 575-82. doi: 10.1016/S1470-2045(11)70097-3

4. Zadnik V, Primc Zakelj M, Lokar K, Jarm K, Ivanus U, Zagar T. Cancer burden in Slovenia with with the time trends analysis. Radiol Oncol 2017; 51: 47-55. doi: 10.1515/raon-2017-0008

5. Stiggelbout AM, Kunneman M, Baas-Thijssen MC, Neijenhuis PA, Loor AK, Jägers S, et al. The EORTC QLQ-CR29 quality of life questionnaire for colorectal cancer: validation of the Dutch version. Qual Life Res 2016; 25: 1853-8. doi: 10.1007/s11136-015-1210-5

6. Marventano S, Forjaz MJ, Grosso G, Mistretta A, Giorgianni G, Platania A, et al. Health related quality of life in colorectal patients: state of the art. $B M C$ Surg 2013; 13 (Suppl 2): S15. doi: 10.1186/1471-2482-13-S2-S15
7. Pucciarelli S, Bianco P, Toppan P, Serpentini S, Efficace F, Pasetto LM, et al. Health-related quality of life outcomes in disease-free survivors of mid-low rectal cancer after curative surgery. Ann Surg Oncol 2008; 15: 1846-54. doi: 10.1245/s10434-008-9923-0

8. Luckett T, King MT, Butow PN, Oguchi M, Rankin N, Price MA, et al. Choosing between the EORTC QLQ-C30 and FACT-G for measuring health-related quality of life in cancer clinical research: issues, evidence and recommendations. Ann Oncol 2011; 22: 2179-90. doi: 10.1093/annonc/mdq721

9. Aaronson NK, Ahmedzai S, Bergman B, Bullinger M, Cull A, Duez NJ, et al. The European Organisation for Research and Treatment of cancer QLQ-C30: a quality-of-life instruments for use in international clinical trials in oncology. J Natl Cancer Inst 1993; 85: 365-76.

10. Life ESG qQo. EORTC QLQ-C30 (version 3.0) Slovenian. Brussels: EORTC 1996.

11. Velenik V, Secerov-Ermenc A, But-Hadzic J, Zadnik V. Health-related quality of life assesed by the EORTC QLQ-C30 questionnaire in the general Slovenian population. Radiol Oncol 2017; 51: 342-350. doi: 10.1515/raon-2017-0021

12. Gujral S, Conroy T, Fleissner C, Sezer O, King PM, Avery KN, et al. European Organisation for Research and Treatment of Cancer Quality of Life Group Assessing quality of life in patients with colorectal cancer: an update of the EORTC quality of life questionnaire. Eur J Cancer 2007; 43: 1564-73. doi:10.1016/j.ejca.2007.04.005

13. Sahay TB, Gray RE, Fitch M. A qualitative study of patient perspectives on colorectal cancer. Cancer Pract 2000; 13: 38-44 doi:10.1046/j.15235394.2000.81012.x

14. Rauch P, Miny J, Conroy T, Neyton L, Guillemin F. Quality of life among disease-free survivors of rectal cancer. J Clin Oncol 2004; 22: 354-60. doi: 10.1200/jco.2004.03.137

15. Arnt V, Merx H, Stegmaier C, Ziegler H, Brenner H. Quality of life in patients with colorectal cancer 1 year after diagnosis compared with the general population: a population-based study. J Clin Oncol 2004; 22: 4829-36. doi:10.1200/jco.2004.02.018

16. Jansen L, Koch L, Brenner $\mathrm{H}$, Arndt V. Quality of life among long-term ( $\geq 5$ years) colorectal cancer survivors - systematic review. Eur J Cancer 2010; 46: 2879-88. doi: 10.1016/j.ejca.2010.06.010

17. Ramsey SD, Berry K, Moinpour C, Giedzinska A, Andersen MR. Quality of life in long term survivors of colorectal cancer. Am J Gastroenterol 2002; 97: 1228-34. doi: 10.1111/j.1572-0241.2002.05694.x

18. Adams SV, Ceballos R, Newcomb PA. Quality of life and mortality of longterm colorectal cancer survivors in the Seattle colorectal cancer family registry. PLOS ONE 2016; 11: e0156534. doi:10.1371/journal.pone.0156534

19. Averyt JC, Nishimoto PW. Psychosocial issues in colorectal cancer survivorship: the top ten questions patients may not be asking. J Gastrointest Oncol 2014; 5: 395-400. doi: 10.3978/j.issn.2078-6891.2014.058

20. Juul T, Petersen MA, Holzner B, Laurberg S, Christensen P, Grønvold M. Danish population-based reference data for the EORTC QLQ-C30: associations with gender, age and morbidity. Qual Life Res 2014; 23: 2183-93. doi: 10.1007/s11136-014-0675-y

21. Hjermstad MJ, Fayers P M, Bjordal K, Kaasa S. Health-related quality of life in the general Norwegian population assessed by the European Organization for Research and Treatment of Cancer Core Quality-ofLife Questionnaire: the QLQ=C30 (+ 3). J Clin Oncol 1998; 16: 1188-96. doi:10.1200/jco.1998.16.3.1188

22. Derogar M, van der Schaaf M, Lagergren P. Reference values for the EORTC QLQ-C30 quality of life questionnaire in a random sample of the Swedish population. Acta Oncol 2012; 51: 10-16. doi: 10.3109/0284186X.2011.614636

23. Schmidt CE, Bestmann B, Kuchler T, Longo WE, Kremer B. Impact of age on quality of life in patients with rectal cancer. World J Surg 2005; 29: 190-97. doi:10.1007/s00268-004-7556-4

24. Sapp AL, Trentham-Dietz A, Newcomb PA, Hampton JM, Moinpour CM, Remington PL. Social networks and quality of life among female longterm colorectal cancer survivors. Cancer 2003; 98: 1749-58. doi:10.1002/ cncr.11717

25. Trentham-Dietz A, Remington PL, Moinpour CM, Hampton JM, Sapp AL, Newcomb PA. Health-related quality of life in female long-term colorectal cancer survivors. The Oncologist 2003; 8: 342-49. doi: 10.1634/theoncologist.8-4-342

26. Hamashima C. Long-term quality of life of postoperative rectal cancer patients. J Gastroenterol Hepatol 2002; 17: 571-76. doi: 10.1046/j.14401746.2002.02712.x

27. Klemm P, Miller M A, Fernsler J. Demands of illness in people treated for colorectal cancer Oncol Nurs Forum 2000; 27: 633-39. PMID: 10833692 